\title{
The Process Matters \\ Fairness in Repository Siting For Nuclear Waste
}

\author{
Journal Article \\ Author(s): \\ Krütli, Pius; Stauffacher, Michael (D); Pedolin, Dario; Moser, Corinne; Scholz, Roland W. \\ Publication date: \\ 2012-03 \\ Permanent link: \\ https://doi.org/10.3929/ethz-b-000047895 \\ Rights / license: \\ In Copyright - Non-Commercial Use Permitted \\ Originally published in: \\ Social Justice Research 25(1), https://doi.org/10.1007/s11211-012-0147-x
}




\title{
The Process Matters: Fairness in Repository Siting For Nuclear Waste
}

\author{
Pius Krütli • Michael Stauffacher • Dario Pedolin • \\ Corinne Moser $\cdot$ Roland W. Scholz
}

Published online: 9 February 2012

(C) Springer Science+Business Media, LLC 2012

\begin{abstract}
Siting contested infrastructure such as repositories for nuclear waste very often faces strong local resistance. One major reason for this opposition may arise because siting processes do not appropriately consider fairness issues such as transparency, the availability of options, or the sufficient involvement of concerned and affected people. The aim of this study was to analyze people's concerns related to justice in siting nuclear waste. Besides procedural aspects, both distributive justice and outcome valence are considered important and therefore the "total fairness model" by Törnblom and Vermunt (Soc Justice Res 12:39-64, 1999) was used as a framework. In three quasi-experimental studies $\left(N_{1}=53 ; N_{2}=56\right.$; $N_{3}=83$ ) applying conjoint analysis, respondents ranked 11 vignettes with the three attributes procedural justice, distributional justice, and outcome valence. Each vignette represents a realistic scenario of a site selection process for the disposal of nuclear waste in Switzerland. All the three studies yield a consistent result: vignettes representing a situation with a fair process are top-ranked by respondents; situations with negative outcome valence are ranked lowest; distributive issues turned out to be of minor importance. We conclude that procedural fairness should be given more attention in any kind of contested infrastructure siting and that real-world examples like the one discussed here can inform justice research.
\end{abstract}

Keywords Procedural fairness - Distributive justice - Outcome valence · Total fairness model $\cdot$ Conjoint analysis · Siting nuclear waste repository

P. Krütli $(\bowtie) \cdot$ M. Stauffacher · D. Pedolin · C. Moser · R. W. Scholz ETH Zurich, Institute for Environmental Decisions-Natural and Social Science Interface, Universitätstrasse 22, CHN J 71, 8092 Zurich, Switzerland e-mail: pius.kruetli@env.ethz.ch 


\section{Introduction}

Justice issues have been discussed theoretically for decades in repository siting (KASAM, 1988; Kasperson, 1983; Stern \& Fineberg, 1996), and the relevance of a fair procedure has been emphasized repeatedly (Renn, Webler, \& Wiedemann, 1995; Sjöberg \& Drottz-Sjöberg, 2001). However, the importance of (procedural) justice issues has rarely been demonstrated empirically, and fairness ${ }^{1}$ issues in the contextualized situation of the repository site selection process are still not well understood. From a policy maker's point of view, this is an important issue, as appropriate and accepted repository sites have to be found, independently of phasing out nuclear energy.

In the site selection process for the deep geological disposal of nuclear waste, extensive involvement of affected people is generally viewed as a necessity (NEA, 1999; Stern \& Fineberg, 1996). Stepwise, transparent and flexible procedures which include clear rules and responsibilities of the subjects (Pescatore \& Vari, 2006) are considered key to site selection. However, technical requirements and constraints compete with procedural and distributive fairness (DF). For example, an even distribution of the burden ${ }^{2}$ cannot be achieved for managerial and safety reasons. ${ }^{3}$ Disposal options (distributive aspect) are restricted depending on the country's specific geological conditions, which limit the potential siting areas. Salt, granite, and argillaceous rock are considered appropriate bedrocks (Witherspoon \& Bodvarsson, 2001) for deep geological disposal, the generally considered best option for long-term management of (high-level) radioactive waste (NEA, 2008). These limits contrast with the benefits, which are available to all the members of society, such as electricity produced in nuclear power plants, medical diagnosis and therapy, and industrial applications. Furthermore, as technical issues are predominantly a matter for skilled experts (Krütli, Stauffacher, Flüeler, \& Scholz, 2010) the incorporation of (technical) safety restricts procedural opportunities for concerned and affected people. On the other hand, fundamental opposition to the use of nuclear power (e.g., Rosa \& Freudenberg, 1993; Surrey \& Huggett, 1976) and the debate on future energy strategies influence the site selection process (Stauffacher, Krütli, \& Scholz, 2008). Thus, procedure, outcome, and distribution are related sources of concern in the case of nuclear waste repositories.

\footnotetext{
${ }^{1}$ The terms fairness and justice will be used interchangeably throughout the article.

${ }^{2}$ From a technical point of view the disposal of radioactive waste can be managed safely in the long run (Nagra, 2002). Therefore, the term burden is not restricted to risk issues but relates to material costs (e.g., decrease in property prices), as well as immaterial costs (e.g., stigmatization of a host region, shift of energy-political arguments from national to regional level) (Rawles, 2002).

${ }^{3}$ Management strategies usually distinguish two fractions of waste according to the concentration of radio-nuclides and the decay periods, namely low- and intermediate-level waste, and high-level waste including spent fuel. This calls for different isolation strategies relating to time and area, i.e., radioactive waste has to be isolated from the biosphere for hundreds (low-level waste) to hundreds of thousands of years (high-level waste). Near-surface facilities are considered appropriate for the disposal of low-level waste, while deep geological repositories (several hundreds of meters below surface level) are necessary for high-level waste (IAEA, 1994). Switzerland, for example, is currently planning two repositories in geological formations: one to dispose of low- and intermediate-level waste, another to store high-level waste. This is a common strategy in other countries as well.
} 
$t$ is well documented that a fair procedure can affect the perception of an outcome and even the acceptance of an unfavorable result. This "fair process effect" (Folger, Rosenfield, Grove, \& Corkran, 1979) was first demonstrated in the early 1970s by the research of Thibaut and Walker (1975) in the framework of legal procedures. People would give up decision control if process control (i.e., people having a say, or "voice," in the process) were guaranteed. Many scholars have replicated Thibaut and Walker's findings, predominantly in organizational settings (for a review see Colquitt, Conlon, Wesson, Porter, \& Ng, 2001; Folger \& Cropanzano, 1998), however, to our knowledge, not in the context of nuclear waste management.

One long-lasting debate in justice research has centered around whether procedural fairness (PF) is more important than DF and vice versa (e.g., Lind \& Tyler, 1988; Törnblom \& Vermunt, 2007b; van den Bos, Lind, \& Wilke, 2001). Leventhal (1980), for example, suggested that individuals who feel dissatisfied with a distribution give procedural rules more weight, while distributive justice becomes more important when procedural justice is violated. Tyler, Boeckmann, Smith, \& Huo (1997) argue that in criminology, procedural justice is a more important factor than distributive justice. These findings are challenged by a current study of Törnblom and Kazemi (2010). They found in the context of physical abuse and theft that respondents perceive procedural justice to be less important than the outcome for both serious and moderate offenses. A similar result was reported by Earle and Siegrist (2008), arguing that PF in the context of environmental risk management may become of minor importance if individuals have a strong stake in the issue at hand. Yet it lacks a framework or a theory suggesting under what conditions procedural justice is more important than distributive justice and vice versa: "Future developments ... need to include ... the social context and type of resources involved, as well as the identification of which distributive and procedural principles are honored or violated to yield a situation of justice or injustice." (Kazemi \& Törnblom, 2008, p. 223). We assume that in repository siting people are more concerned about PF than distributive issues, yet this has not been empirically analyzed so far.

With respect to the trade-off between process and outcome, the concept of "protected values" (Baron \& Spranca, 1997) has been discussed in recent yearssimilar concepts are called "sacred value," "taboo trade-offs" (Tetlock, 2003) or "moral mandate" (Skitka, 2002). Such protected values presumably compete with PF (Skitka \& Mullen, 2002) as they are considered to be absolute and fixed, not allowing for trade-offs, substitution or sacrifice with or for other values (Tanner, Ryf, \& Hanselmann, 2009). Consequently, Skitka (2002, p. 590) argues that the "impact of procedural fairness on outcome judgments ... will be mitigated (or eliminated) when people have a strong moral mandate." This may hold true for radioactive waste management. One aspect might be that people do not want to have the pristine underground contaminated by hazardous waste. Another reason worth mentioning in this respect is that groups opposing the use of nuclear energy may have such "sacred values," and may be against the disposal of nuclear waste for tactical purposes.

It makes a difference whether a benefit or a burden is distributed. People's fairness judgments will be influenced not only by the allocation (e.g., Deutsch, 1975) and the allocation process (e.g., Tyler, 1988; van den Bos, Wilke, Lind, \& Vermunt, 1998) but also by the valence of the outcome (OV) (Törnblom, 1988), 
i.e., whether the outcome is perceived positively or negatively. Törnblom and Vermunt (1999) integrated PF and DF and the notion of outcome valence into an overall composite, their "total fairness model," arguing that people "conceive the fairness of a situation as Gestalt, as an integrated system with constituent parts" (ibid., p. 51). In general, people perceive a repository for nuclear waste as a burden (BFE, 2008a). However, as construction and operation of such a repository might contribute to the local economy, some people can consider it as a benefit as well. How outcome valence interplays with procedural and distributive issues has, however, not been tested in empirical research about nuclear waste.

Repository siting includes technical and non-technical issues. From a safety perspective we have to find the "best" site. The repository siting concept set up by the Swiss Federal Office of Energy (BFE, 2008b) includes a three-stage procedure that starts from a number of potential host sites and continues to a stepwise narrowing down of the options, with technical safety as a major criterion. This at least 10-year long procedure, on the other hand, includes extensive participatory options for the people concerned. The siting process and people's concerns may be affected by the controversy on the further use of nuclear energy. This particular nature of the decision problem makes it a theoretically interesting case to investigate. Our study therefore aims at analyzing people's concerns about fairness in decisions on nuclear waste repository siting. A special focus will be given to the analysis of PF, as this might become a major issue in current and upcoming siting processes all over the world (Krütli, Flüeler, Stauffacher, Wiek, \& Scholz, 2010; NEA, 2008). It is relevant for policy-maker to learn more about how a fair process impacts people's judgment of a given contextualized situation. Recognizing that justice is a multi-faceted concept and fairness judgments include a multitude of personal and contextual issues, we concentrate on three dimensions considered important in the issue at hand: procedural and distributive issues and the general energy policy context. To appropriately tackle this case, we use the "total fairness model" of Törnblom and Vermunt (1999) as guidance; follow the siting concept of the Swiss Federal Office of Energy (BFE, 2008b) to design the decision situation; and apply conjoint analysis (CA) to investigate people's trade-offs in their fairness judgments. We have people assess close-to-reality decision situations that include three attributes $(\mathrm{PF}, \mathrm{DF}$, and $\mathrm{OV}$ ) to gain insights into their preferences for $\mathrm{PF}$, and specifically to answer the question: does process matter? As we are interested in main effects only, i.e., which attribute is most preferred, CA is considered an appropriate technique.

\section{Methods}

In the following, we first present some details on the CA method. We then provide information about the decision situations (vignettes) to be assessed by subjects and give some general information about the procedure of data collection and the data processing. More detailed methodological information will be given in the respective paragraphs presenting the individual studies. 
Conjoint Analysis Method

$\mathrm{CA}$ is a method for studying complex decision situations where more than one factor influences the decision (Green \& Srinivasan, 1978; Luce \& Tukey, 1964), i.e., it is designed to assess the impact of individual attributes on the overall utility of an object like a product or service (Gustafsson, Hermann, \& Huber, 2007). CA is a decompositional method, i.e., the overall evaluation of an object can be split up into the (relative) importance of different attributes (e.g., form, color, material of a product) (Alriksson \& Öberg, 2008). It is an indirect measurement of the attributes, which reduces the potential for strategic responses (Sattler \& Hensel-Börner, 2007), and may thus better reflect revealed preference (Green \& Srinivasan, 1990). It provides part-worth utilities of all attribute-levels (e.g., form: round, square, or angular; color: yellow, brown, or blue; material: leather, plastic, or wood). CA is an additive model (Backhaus, Erichson, Plinke, \& Weiber, 2006; for methodical details see Klein, 2002), i.e., the part-worth utilities of all the attribute-levels add up to the total utility of an object, referred to as vignettes in CA (see Formula 1: general additive model of CA)

$$
y_{k}=\sum_{j=1}^{j} \sum_{m=1}^{M_{j}} \beta_{j m} \cdot x_{j m}
$$

where $y_{k}$ is the estimated overall utility of stimulus $k ; \beta_{j m}$ is the part-worth utility of attribute-level $m$ of attribute $j ; x_{j m}=1$ if stimulus $k$ includes attribute $j$ and attribute-level $m$; if not 0 .

The strength of classical CA is that it does not need a ranking of all the possible combinations of attribute and attribute-levels. CA estimates utilities of all the possible vignettes, based on a minimal number of vignettes. This so-called orthogonal design is a set in which each level of an attribute is combined only once with any level of other attributes. Thereby, the number of vignettes to be ranked can be significantly reduced. All the other vignette utilities can be estimated out of the information provided by the ranked set of vignettes. The method provides estimates on both the individual and the aggregated levels (Backhaus et al., 2006; cf. Ratcliffe, 2000). Classical CA provides main effects only, and its potential to study interaction effects is limited (Green \& Srinivasan, 1990) or needs design modification (Gustafsson et al., 2007). CA approaches other than ranking, such as paired comparison, rating, and choice experiments, have been used and described as well (e.g., Alriksson \& Öberg, 2008). Similar techniques exist under the name of factorial survey (cf. Rossi \& Nock, 1982). The underlying rationale is the same as in CA, i.e., both the approaches combine principles of experimental design and survey procedures (e.g., Alexander \& Becker, 1978; Beck \& Opp, 2001; Jasso, 2006; Wallander, 2009). In contrast to factorial measurement, where respondents generally rate vignettes on a given scale, classical CA is a ranking method, "a technique for measuring trade-offs for analyzing survey responses concerning preferences and intentions" (Green, Krieger, \& Wind, 2001, p. S57), which allows for measuring trade-offs between the attributes and making visible respondents' relative attribute preference (referred to as importance of the attribute). 


\section{Vignettes}

Three different attributes (PF, DF, and OV) following the "total fairness model" of Törnblom and Vermunt (1999) were formulated to include three different levels for each attribute. Together they represent potential, contextualized decision situations of a repository site selection process for nuclear waste. To generate realistic decision situations we closely followed the stepwise approach for the selection of a site for the final disposal of radioactive waste in Switzerland (BFE, 2008b) as mentioned above.

\section{Procedural Fairness}

Webler and Tuler (2000) derived seven categories of principles for participation. Four of these categories are fairness oriented (Blader \& Tyler, 2003; Gibson, 1989; Leventhal, Karuza Jr, Rick Fry, 1980; Lind \& Tyler, 1988; Thibaut \& Walker, 1978), of which two categories "access to the process," "power to influence process and outcomes" are in line with Thibaut and Walker's (1975) findings. The other two categories "facilitate constructive interaction" and "access to information" (Webler \& Tuler, 2000, pp. 576-577) fit in with Leventhal's (1980) procedural justice criteria such as "ethicality" and "accuracy." A research project on governing nuclear waste management identified 17 procedural principles as relevant, among which were stepwise approach, transparency, control of the process, balanced values and interests (COWAM 2, 2007). In line with these findings, we use "voice" (i.e., having a say) as a major criterion in our study to denote the fairness of a procedure, and we include bindingness of the procedure, intensity of information, and form of expertise as further criteria. Attribute-levels of PF range from no (considered unfair) to maximal (considered fair) voice (see Table 1).

\section{Distributive Fairness}

Equity, equality, and need are widely acknowledged to be major allocation rules (e.g., Deutsch, 1975). The equality principle can be eliminated a priori due to the one repository principle (see "Introduction"). Thus, the equity principle seems to be a suitable alternative. One can argue that the fairest option is for the region that benefits most from nuclear power (e.g., through the use of electricity) to become the host area. This principle is included in the attribute-level considered just. The need principle would exclude those regions which are already burdened by other infrastructure facilities and risks. A further option would be the utilitarian principle. According to this principle, the repository should be built in a region with the lowest number of affected people, i.e., it should limit the presumed burden for a maximal number of people. This principle was most favored by respondents of a survey $(N=2,368)$ in Switzerland (Stauffacher et al., 2008) and was therefore included in the design (see Table 1). Voluntariness was included as a third attribute-level as this approach had been discussed in other countries such as Sweden or Canada (Gunderson \& Rabe, 1999). Note that the distributive rules will be applied under the 
Table 1 Attribute and attribute-levels

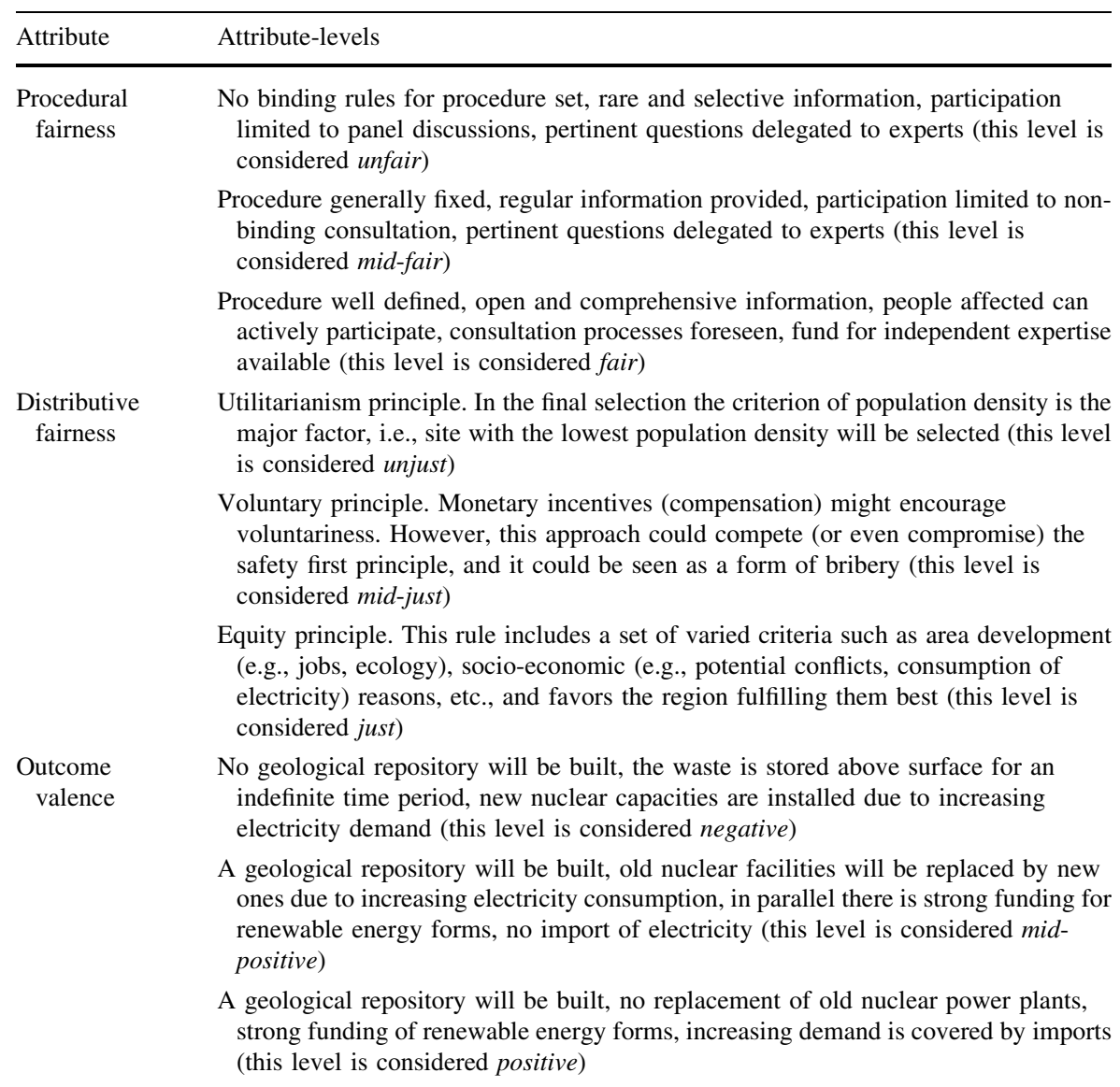

Notes attributes and their corresponding three different attribute-levels. The vignettes represent a combination of attribute and attribute-levels

condition that several sites with appropriate geological minimum ${ }^{4}$ conditions are considered.

\section{Valence of the Outcome}

In line with Törnblom and Vermunt (1999), we assume that it might be relevant for people's judgment whether the outcome is (perceived) to be positive or negative. Furthermore, the issue of radioactive waste is value laden, as history shows, and the connection to nuclear energy is obvious. Two major elements might stand for the OV: first, whether a geological repository will be built or not, and, second, whether nuclear energy will continue to be produced or not. The latter refers to the concept

\footnotetext{
${ }^{4}$ For epistemological reasons it is not possible to find the safest site. Rather a site must fulfill a number of several predefined criteria and minimal requirements, such as seismic activity, hydraulic conductivity, homogeneity, extent, thickness and depth of potential host rock (Flüeler, 2006).
} 
of "sacred value" and might influence people's fairness judgments as respondents might negatively value continuation of nuclear energy production. Additional issues such as renewable energy and importing electricity are considered important contextual factors and are therefore included as well. Three attribute-levels were designed (see Table 1).

\section{Data Collection: General Procedure}

Three consecutive quasi-experimental studies were conducted between December 2008 and May 2009. Subjects were provided with a dossier ${ }^{5}$ consisting of brief information about the goal of the study; instructions on how to proceed; 11 vignettes, each on a single sheet (randomly ordered); questionnaires, including socio-demographic and further explanatory variables; background information both on the issue and on the study in a sealed envelope to be opened after finishing.

Subjects ranked 11 vignettes including three different attributes with the three attribute-levels each (note exceptions in Study 3) according to personal preferences, from most preferred (Rank 1) to least preferred (Rank 11). To better capture the information, the vignette attributes were presented in different colors. Subjects were asked to carefully read each vignette, to summarize it in note form, and to fill in a matrix with specific characteristics of each vignette to better find differences and similarities. In Studies 2 and 3, subjects additionally rated three distinct vignettes on a given scale under the perspective of fairness (for details see respective paragraphs presenting studies). In Study 3, the attribute outcome valence was split into two attributes.

\section{Computation}

Altogether, this led to a $3 \times 3$ factorial design (see Table 1) including PF (unfair, mid-fair, and fair), DF (unjust, mid-just, and just), and the OV (negative, midpositive, and positive), and results in $3^{3}=27$ combinations (vignettes) of alternative decision situations. A reduced design comprising nine vignettes (see Table 2 for an example) represents a sufficient number to be assessed by subjects. This reduced design is provided by the statistical computer software SPSS. Two additional vignettes represent holdout $\operatorname{cases}^{6}$ to check on the validity of the model, and the estimates, respectively.

The ranking of these 11 vignettes provides the basis for estimating the part-worth utilities of attribute-levels and the importance of the attributes, and finally the overall utilities of all the 27 vignettes. The data were analyzed by the SPSS software package (version 17).

\footnotetext{
5 The full dossier including detailed instructions on how to process the ranking task, all the 11 vignettes, further explanatory items and socio-demographic variables will be provided by the first author on request. All the information is in German only.

${ }^{6}$ Subjects ranked holdout cases (vignettes), which, however, are not used to construct the preference model. Conjoint procedure computes correlations (Kendalls' $\tau$ ) between the predicted and the observed rank order for these profiles, representing a check on the validity of utilities.
} 
Table 2 Example of a vignette

\begin{abstract}
The site selection procedure is well defined and transparent, open and comprehensive information is provided, the affected population is invited to actively participate in the decisionmaking process and may articulate their interests, the affected will be consulted in relevant aspects, a fund for independent expertise is available

A site has to be selected out of several regions providing (similar) appropriate safety conditions, in this final site selection step population density is the core criterion, i.e., the region featuring the lowest population density will be selected, the Swiss Federal Council takes the decision

\section{A geological repository for radioactive waste will be built, the power consumption increases due to continuing electrification, for that reason it was recently decided to replace old nuclear power plants by new ones, simultaneously renewable energy systems will be funded strongly, no further import of electricity power is allowed}

Notes this vignette (out of 11 vignettes evaluated by the subjects) represents the attribute-levels $\mathrm{PF}=$ fair, $\mathrm{DF}=$ unjust, $\mathrm{OV}=$ mid-positive (see Table 1). To facilitate comparison between the vignettes, each attribute was differently colored (here illustrated in different gray scales)

\title{
Present Studies
}

In the following, three consecutive studies will be presented. The goal of Study 1 was to assess subjects' relative preferences regarding the three attributes, and the principal applicability of $\mathrm{CA}$ in the issue at hand, respectively. People from academia were considered appropriate for this purpose. Study 2 was meant to be a replication of Study 1. To further analyze the stability of the measurement a different group of subjects was included. In Study 3, some modifications in the design were made. Note that Studies 1 and 2 will be presented together while Study 3 will be presented separately.

\section{Studies 1 and 2}

\section{Method: Subjects and Procedure}

The subjects in Study $1(N=53)$ were volunteers from academia, basically students (age: $M=27 ; S D=7.65$; male $n=32$, female $n=21$ ) from the ETH and University of Zurich. The subjects' academic background is natural science/engineering/ mathematics $(n=42)$ or social science/humanities/economics $(n=11)$. Data collection took place between November and December 2008 in small groups or individually in a laboratory room. Subjects took $45-70$ min to complete the study.

A total of 56 Swiss German volunteers from outside academia and outside the greater Zurich area (age: $M=49 ; S D=13.56$; male $n=26$, female $n=30$ ) participated in Study 2. Of the group, $75 \%$ had completed secondary education and $25 \%$ had a tertiary education degree. Data collection was slightly different compared with Study 1. Subjects were individually given or posted the same dossier as in Study 1, consisting of self-explanatory documents and a cover letter. In all, 62 out of 80 dossiers were returned, of which 6 dossiers had to be excluded due to 
obvious misinterpretations or incompleteness. Subjects reported taking up to two hours to complete the task.

$\mathrm{CA}$ in principle calls for preference rankings and computes utility values. One could argue that this does not reflect fairness judgments (Liebig, 2001). Therefore, items involving the rating of vignettes from the perspective of fairness were included in Study 2 to analyze the difference between preference and fairness judgments (Skitka, 2003): in addition to the rankings, subjects evaluated three distinct vignettes from the perspective of fairness to provide a reference measure for the overall fairness/unfairness of the respective decision situation and to better classify the ranking results. The three vignettes are: vignette (i) which subjects preferred most (Item: "Please assess the vignette you mostly prefer under the perspective of fairness" ${ }^{7}$ ); (ii) which was considered fair; and (iii) unfair by the authors. Note that in both (ii) and (iii) the level of OV was kept stable. The "most preferred" vignette was included to analyze the effect of the attribute OV in the overall judgments.

\section{Results}

Computation provides both part-worth utilities of all the attribute-levels shown in Fig. 1 and importance values (Table 3). Unfair procedures and unjust distributive rules as well as negative outcome valence provide negative part-worth utilities and vice versa. Furthermore, a fair process contributes most to the overall utility of a vignette, whereas a negative outcome impacts the overall utility of the corresponding vignettes most negatively. Note that the decision to build a repository positively affects the overall utility of a vignette, though it is striking that whether this happens with or without new nuclear facilities is rather irrelevant (Fig. 1).

The importance of an attribute is the result of the range between lowest and highest part-worth utility of its attribute-levels (spread). It indicates subject's preference regarding the respective attribute. It becomes evident from Fig. 1 that outcome valence is the most important attribute, in Study 1 accounting for $47 \%$ (48\% in Study 2) of total importance (all the three attributes add up to $100 \%$ ). PF accounts for 30\% (34\% in Study 2) and distributive justice for 23\% (18\% in Study 2 ). That is, the $\mathrm{OV}$ is a major factor and a variation within this attribute will have the most significant effects on the total utility of a vignette. Interestingly, the final selection of a site according to either the "voluntary principle" or the criterion of "population density" negatively affects the overall utility, but the "equity principle" affects it positively.

Table 3 shows all the 27 possible vignettes of Study 2 ordered according to the measured preference (rankings) and estimated utility scores ranging from 1.78 (lowest) to 7.53 (highest), respectively. One can, first, observe that vignettes which include the attribute-level OV "negative" represent the least preferred vignettes: all but 3 are bottom-ranked (in Study 1, all but 2). The corresponding justice attributelevels are unfair/unjust (5), mid-fair/mid-just (5), and fair/just (2). At the other end of the spectrum we find 6 of 9 vignettes which include the attribute-level PF fair

\footnotetext{
$\overline{7}$ Translation from German by the authors.
} 


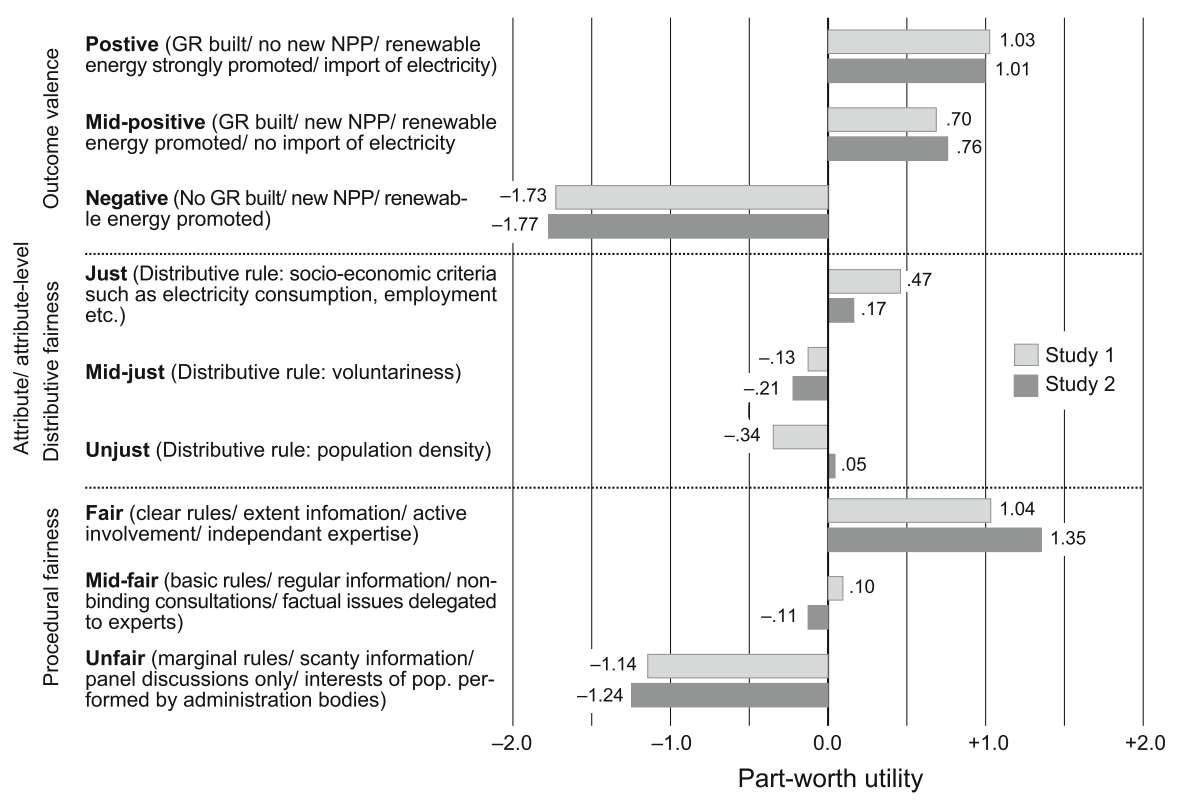

Fig. 1 Part-worth utilities of Studies 1 and 2. Aggregated part-worth utilities of all the attribute-levels of Study $1(N=53)$ and Study $2(N=56)$. The utility estimates of the attribute-levels vary positively or negatively from the basis utility ( 5.00 for both studies corresponding to the average rank). The overall utility of a vignette is calculated (additively) from the basis utility and the part-worth utilities of the attribute-levels of all three factors of the corresponding vignette. GR geological repository, NPP nuclear power plant

top-ranked (in Study 1, 5 of the 9). The corresponding DF and OV attribute-levels are just/positive (2/3), mid-just/mid-positive (2/3), and unjust/negative (2/0). In other words, the situation where no geological repository will be built in combination with both further use of nuclear energy and the promotion of renewable energy is the least preferred situation while vignettes which represent both a fair decision-process and a positive/mid-positive outcome are most preferred. Study 1 provides very similar results (not shown).

In Study 2, in addition to the vignette ranking, subjects judged three vignettes from the perspective of fairness (Table 4). The fair/just vignette (corresponds to vignette no. 26 in Table 3) scored $M=4.06$ on a 6-point scale, $S D=1.39$ while the unfair/unjust one scored $M=1.77, S D=1.04$ (corresponds to vignette no. 19 in Table 3). Furthermore, subjects chose the vignette which they preferred most (i.e., Rank 1) under the same consideration. The vignette scored highest $(M=4.76$, $S D=1.09)$ and 41 out of 56 respondents $(73 \%)$ ranked vignettes no. 21 or 22 top (Rank 1, Table 3), both representing a fair process.

\section{Discussion}

The data suggest that our assumptions regarding the attribute-levels are correct, i.e., fair process, just distribution, and positive outcome yield positive part-worth utilities; while unfair, unjust, and negative provide negative part-worth utilities. 
Table 3 Simulation of all the vignettes of Study 2
Notes Estimated utility scores of all the vignettes of Study 2. To better illustrate the pattern of the vignette preferences the corresponding levels of the attributes have a different gray scale (NB: Study 2 is presented only, but the pattern of Study 1 is very similar). Correlations between observed and estimated preferences (validity measure): Study 1, Kendall's $\tau=.94$; Study 2, Kendall's $\tau=.94$

a Corresponds to vignettes evaluated (ranked) by subjects used for computation

b Vignettes evaluated by subjects used as holdout cases to estimate validity

\begin{tabular}{|c|c|c|c|c|}
\hline \multirow{2}{*}{$\begin{array}{c}\text { Card } \\
\text { no. } \\
\text { (vignette) }\end{array}$} & \multirow[b]{2}{*}{$\begin{array}{l}\text { Overall } \\
\text { utilities }\end{array}$} & \multicolumn{3}{|c|}{ Attribute/attribute-levels } \\
\hline & & $\begin{array}{c}\text { Procedural } \\
\text { fairness }\end{array}$ & $\begin{array}{l}\text { Distributive } \\
\text { fairness }\end{array}$ & $\begin{array}{l}\text { Outcome } \\
\text { valence }\end{array}$ \\
\hline 16 & 7.53 & Fair & Just & Positive \\
\hline 6 & 7.41 & Fair & Unjust & Positive \\
\hline 15 & 7.27 & Fair & Just & Mid-positive \\
\hline $22^{\mathrm{a}}$ & 7.15 & Fair & Unjust & Mid-positive \\
\hline $21^{\mathrm{a}}$ & 7.15 & Fair & Mid-just & Positive \\
\hline 11 & 6.89 & Fair & Mid-just & Mid-positive \\
\hline 14 & 6.06 & Mid-fair & Just & Positive \\
\hline $25^{\mathrm{a}}$ & 5.95 & Mid-fair & Unjust & Positive \\
\hline $27^{\mathrm{a}}$ & 5.81 & Mid-fair & Just & Mid-positive \\
\hline 4 & 5.69 & Mid-fair & Unjust & Mid-positive \\
\hline 9 & 5.68 & Mid-fair & Mid-just & Positive \\
\hline 8 & 5.43 & Mid-fair & Mid-just & Mid-positive \\
\hline $18^{\mathrm{a}}$ & 4.94 & Unfair & Just & Positive \\
\hline 2 & 4.82 & Unfair & Unjust & Positive \\
\hline $26^{\mathrm{a}}$ & 4.75 & Fair & Just & Negative \\
\hline 13 & 4.68 & Unfair & Just & Mid-positive \\
\hline 5 & 4.63 & Fair & Unjust & Negative \\
\hline 1 & 4.56 & Unfair & Unjust & Mid-positive \\
\hline 7 & 4.56 & Unfair & Mid-just & Positive \\
\hline 10 & 4.37 & Fair & Mid-just & Negative \\
\hline $17^{\mathrm{a}}$ & 4.30 & Unfair & Mid-just & Mid-positive \\
\hline $23^{\mathrm{b}}$ & 3.29 & Mid-fair & Just & Negative \\
\hline 3 & 3.17 & Mid-fair & Unjust & Negative \\
\hline $24^{\mathrm{a}}$ & 2.90 & Mid-fair & Mid-just & Negative \\
\hline 12 & 2.16 & Unfair & Just & Negative \\
\hline $19^{\mathrm{a}}$ & 2.04 & Unfair & Unjust & Negative \\
\hline $20^{\mathrm{b}}$ & 1.78 & Unfair & Mid-just & Negative \\
\hline
\end{tabular}

Study 2 yields almost the same results as Study 1 (Fig. 1). This is remarkable, as the samples differ considerably with regard to age and educational level as well as to cultural and occupational status. This indicates that the data collection is robust, which is of practical and theoretical relevance, as it suggests that the response pattern could be found in other population samples as well, and might therefore be generic for given specifics of the issue at hand and under the given justice model (Törnblom \& Vermunt, 1999). OV is scored as being the most important, and data suggest that the presence of a geological repository had a major effect. Subjects did 
Table 4 Fairness judgments Study 2

\begin{tabular}{llllll}
\hline Fairness of vignette & $N$ & Mean & $S D$ & $t$ test (2-tailed) & \\
\hline Most preferred & 55 & 4.76 & 1.09 & $p<.00$ & \\
$\mathrm{PF}_{\text {fair }} / \mathrm{DF}_{\text {just }} / \mathrm{OV}_{\text {negative }}$ & 52 & 4.06 & 1.39 & & $p<.00$ \\
$\mathrm{PF}_{\text {unfair }} / \mathrm{DF}_{\text {unjust }} / \mathrm{OV}_{\text {negative }}$ & 52 & 1.77 & 1.04 & & \\
\hline
\end{tabular}

Notes fairness judgments of vignettes, 6-point scale, 1 (unfair) to 6 (fair)

$P F$ procedural fairness, $D F$ distributive fairness, $O V$ outcome valence

not prefer situations in which no geological repository would be built but at the same time existing nuclear power plants would be replaced by new ones. However, the promotion of renewable energy and the domestic energy supply might have affected subjects' preference rankings as well. The OV was probably overcharged by different sub-attributes such as geological repository, nuclear energy, electricity import, and promotion of renewable energy. This might have contributed to the dominance of this attribute. Yet all these aspects play a role in the real situation and probably affect a final decision.

The rather low importance of DF can be explained by technical-geological constraints, which a priori limit distributional issues (one repository principle, suitable geological conditions). This, furthermore, can explain the dominance of procedural over distributive issues. It is striking that PF provides the highest positive part-worth utility and 6 out of 9 vignettes that include a fair process belong to the most preferred vignettes. This suggests that a fair procedure in the siting process is $a$ conditio sine qua non and one might argue that a fair process would pave the way for acceptance (Lind \& Tyler, 1988).

Subjects' judgments of a set of three distinct vignettes from the perspective of fairness provide interesting results. As mentioned before one can argue that preference ranking does not suitably reflect fairness judgments. A scale-based reference measure was therefore included in Study 2 to better classify CA ranking results and estimates. Fairness judgments (Table 4) fit well with the preference-ranking pattern (Table 3): fair is preferred to unfair. This is relevant as it links the relative rankings of CA with the scale-based overall satisfaction of selected vignettes, and it allows for a clear interpretation of the data provided by CA: a fair decision situation is preferred to an unfair one; the process matters; people's fairness judgments are influenced by contextual factors as well. The latter refers to the most preferred vignette (Rank 1), which scored highest in terms of fairness. This supports the principal idea of the total fairness model, which postulates that the overall fairness of a situation is best judged as an integrated combination of distributive and procedural factors, and the valence of the "phenomenon” (Törnblom \& Vermunt, 2007a).

\section{Study 3}

\section{Method: Modifications}

In Study 3, a few modifications to the design were made. We had learned from Studies 1 and 2 that the attribute OV was probably overloaded with different 
aspects such as renewable energy and electricity imports besides nuclear energy and geological repository. All which might play a role in decision-making on the issue at hand but potentially interacted with and influenced subjects' judgments differently according their personal preferences and mind-sets. Therefore, we excluded all the other aspects except nuclear energy (NPP) and geological repository (GR), to investigate what importance they play in fairness judgments regarding repository siting, and under the given model, respectively. Further, these two aspects were separated into two different attributes each with two levels: yes or no, whereby no geological repository and a new nuclear power plant are considered a negative outcome and vice versa. This results in a total number of $36(3 \times 3 \times 2 \times 2)$ possible decision situations (vignettes). A reduced number of 11 vignettes including 2 holdout cases had to be ranked by respondents. With respect to judgments under the perspective of fairness $\mathrm{PF}_{\text {mid-fair }}$ was selected instead of $\mathrm{PF}_{\text {unfair }}$ to contrast with $\mathrm{PF}_{\text {fair }}$, while $\mathrm{OV}_{\mathrm{GR}}$ and $\mathrm{OV}_{\mathrm{NPP}}$ were kept stable.

\section{Method: Subjects and Procedure}

Eighty-three students (age: $M=24 ; S D=2.83$; male $n=35$, female $n=48$ ) from a Swiss German university for teacher education in the natural sciences participated in the study. The data collection took place between March and May 2009. Subjects were briefly informed about the procedure and were then given the self-explaining study dossier. Seven sessions that included 6-17 students each were conducted in the classroom during lectures. The experimental procedure was performed as described above. Subjects spent between 45 and 80 min on completing the study.

\section{Results}

Computations providing part-worth utilities of all the attribute-levels and importance values for Study 3 are shown in Table 5. As in Studies 1 and 2, both unfair procedures $(-1.88)$ and unjust distributive rules $(-.51)$ as well as negative outcome valence (GR -.32; NPP - .19) provide negative part-worth utilities and vice versa. Furthermore, a fair process contributes the most by far to the overall utility of a vignette (1.83), whereas an unfair procedure impacts the overall utility of the corresponding vignettes most negatively. Note that the contribution of the attribute DF, as well as that of both the OV attributes (GR and NPP) has a rather small influence on the overall judgment of the vignettes. This becomes clear when we compare the importance of the attributes. PF accounts for $45 \%$ of overall importance followed by $\mathrm{DF}(27 \%)$ and $\mathrm{OV}_{\mathrm{NPP}}(15 \%)$ and $\mathrm{OV}_{\mathrm{GR}}(13 \%)$, respectively. The additive $\mathrm{CA}$ model allows for merging $\mathrm{OV}$ factors. This results in a relative importance value of $28 \%$.

The simulation of all the 36 possible vignettes based on the respondents' ranking of 11 vignettes is shown in Table 6. The dominance of PF is striking, and obviously triggered subjects' evaluations. All the vignettes that include a fair site selection procedure are ranked at the top, i.e., they provide the highest overall utilities. All the other attributes seem to be subordinated to the PF attribute. 
Table 5 Part-worth utilities and attribute importance

\begin{tabular}{lllc}
\hline Attribute & Attribute-level & $\begin{array}{l}\text { Part-worth } \\
\text { utility estimate }\end{array}$ & $\begin{array}{c}\text { Attribute } \\
\text { importance (\%) }\end{array}$ \\
\hline Procedural fairness (PF) & Unfair & -1.88 & 44.64 \\
& Mid-fair & .05 & 1.83 \\
& Fair & -.51 & 27.10 \\
Distributive fairness (DF) & Unjust & .09 & 13.16 \\
& Mid-just & .42 & 15.10 \\
Outcome valence (OV), geological repository & Nust & -.32 & .32 \\
Outcome valence (OV), nuclear power plant & Positive (yes) & Negative (yes) & -.20 \\
Constant (basis utility, averaged rank) & Positive (no) & .20 & \\
\hline
\end{tabular}

Notes aggregated part-worth utility estimates of attribute-levels and attribute importance of Study 3 $(N=83)$. The utility estimates of the attribute-levels vary positively or negatively from the basis utility. The total utility of a vignette is calculated (additively) by the constant and the part-worth utilities of the attribute-levels of all the attributes of the corresponding vignette). Note that attribute importance adds up to $100 \%$

Fairness judgments show the same pattern as in Study 2: the vignette considered (1) mid-fair/unjust (vignette no. 14) by us scores $M=2.23, S D=.90$ (4-point scale), the vignette considered (2) fair/just (vignette no. 36) scores $M=3.24$, $S D=.77$, and the vignette (3) most preferred by the subjects scores $M=3.52$, $S D=.66$. The vignette no. 36 was ranked top by 33 out of 80 respondents $(41 \%)$. The differences of means between (1) and (2), and between (2) and (3) are significant $(p<.00$; two-tailed $t$ test).

\section{Discussion}

In Study 3, the design was changed. OV was split into two attributes, and the information given in these two attributes was restricted to nuclear energy (phasing out: yes/no) and geological repository (will be built: yes/no). This is a major change and results in a different ranking pattern and in different part-worth utility estimates compared with Studies 1 and 2. It is striking that PF is by far the most important factor and influences subjects' trade-offs most when they rank vignettes. The dominance of PF was surprising to us although we expected that the importance of outcome valence would decrease, since renewable energy and import of electricity were excluded. It fits, however, with the pattern of Studies 1 and 2, where we also observed rather high importance values for this attribute. Nevertheless, the dominance of PF cannot be fully explained.

The changes in the design include an unequal number of attribute-levels. Both PF and DF consist of three attribute-levels, however, both $\mathrm{OV}_{\mathrm{GR}}$ and $\mathrm{OV}_{\mathrm{NPP}}$ include two levels only. This could have impacted the part-worth estimates and the comparison of importance values may thus be limited. For example, Currim et al. 
Table 6 Simulation of all the vignettes of Study 3

Notes estimated utility scores of all vignettes of Study 3. To better illustrate the pattern of the vignette preferences the corresponding attribute-levels are shaded differently. Correlations between observed and estimated preferences (validity measure): Kendall's $\tau=.92$

$G R$ geological repository, NPP nuclear power plant

a Vignettes evaluated by subjects used for computations

b Vignettes evaluated by subjects used as holdout cases to estimate validity

\begin{tabular}{|c|c|c|c|c|c|}
\hline \multirow[b]{2}{*}{$\begin{array}{l}\text { Card no. } \\
\text { (vignette) }\end{array}$} & \multirow[b]{2}{*}{$\begin{array}{l}\text { Overall } \\
\text { utilities }\end{array}$} & \multicolumn{4}{|c|}{ Attribute/attribute-levels } \\
\hline & & $\begin{array}{c}\text { Procedural } \\
\text { fairness }\end{array}$ & $\begin{array}{l}\text { Distributive } \\
\text { fairness }\end{array}$ & $\begin{array}{c}\text { Outcome } \\
\text { valence }_{\mathrm{GR}}\end{array}$ & $\begin{array}{c}\text { Outcome } \\
\text { valence }_{\mathrm{NPP}}\end{array}$ \\
\hline 35 & 7.94 & Fair & Just & Positive & Positive \\
\hline 31 & 7.61 & Fair & Mid-just & Positive & Positive \\
\hline 34 & 7.54 & Fair & Just & Positive & Negative \\
\hline $36^{\mathrm{a}}$ & 7.29 & Fair & Just & Negative & Positive \\
\hline 30 & 7.22 & Fair & Mid-just & Positive & Negative \\
\hline 28 & 7.01 & Fair & Unjust & Positive & Positive \\
\hline 32 & 6.97 & Fair & Mid-just & Negative & Positive \\
\hline 33 & 6.90 & Fair & Just & Negative & Negative \\
\hline $27^{\mathrm{a}}$ & 6.62 & Fair & Unjust & Positive & Negative \\
\hline $29^{\mathrm{a}}$ & 6.57 & Fair & Mid-just & Negative & Negative \\
\hline 26 & 6.36 & Fair & Unjust & Negative & Positive \\
\hline 23 & 6.16 & Mid-fair & Just & Positive & Positive \\
\hline 25 & 5.97 & Fair & Unjust & Negative & Negative \\
\hline 19 & 5.84 & Mid-fair & Mid-just & Positive & Positive \\
\hline $22^{\mathrm{a}}$ & 5.77 & Mid-fair & Just & Positive & Negative \\
\hline 24 & 5.52 & Mid-fair & Just & Negative & Positive \\
\hline 18 & 5.44 & Mid-fair & Mid-just & Positive & Negative \\
\hline 16 & 5.23 & Mid-fair & Unjust & Positive & Positive \\
\hline 20 & 5.19 & Mid-fair & Mid-just & Negative & Positive \\
\hline 21 & 5.12 & Mid-fair & Just & Negative & Negative \\
\hline 15 & 4.84 & Mid-fair & Unjust & Positive & Negative \\
\hline $17^{\mathrm{a}}$ & 4.80 & Mid-fair & Mid-just & Negative & Negative \\
\hline $14^{\mathrm{a}}$ & 4.59 & Mid-fair & Unjust & Negative & Positive \\
\hline 11 & 4.23 & Unfair & Just & Positive & Positive \\
\hline 13 & 4.20 & Mid-fair & Unjust & Negative & Negative \\
\hline $7^{\mathrm{a}}$ & 3.90 & Unfair & Mid-just & Positive & Positive \\
\hline 10 & 3.84 & Unfair & Just & Positive & Negative \\
\hline 12 & 3.58 & Unfair & Just & Negative & Positive \\
\hline $6^{\mathrm{b}}$ & 3.51 & Unfair & Mid-just & Positive & Negative \\
\hline 4 & 3.30 & Unfair & Unjust & Positive & Positive \\
\hline 8 & 3.26 & Unfair & Mid-just & Negative & Positive \\
\hline $9^{a}$ & 3.19 & Unfair & Just & Negative & Negative \\
\hline $3^{\mathrm{b}}$ & 2.91 & Unfair & Unjust & Positive & Negative \\
\hline 5 & 2.87 & Unfair & Mid-just & Negative & Negative \\
\hline 2 & 2.66 & Unfair & Unjust & Negative & Positive \\
\hline $1^{\mathrm{a}}$ & 2.27 & Unfair & Unjust & Negative & Negative \\
\hline
\end{tabular}

(1981; see also Wittink, Krishnamurthi, \& Nutter, 1982) found that attributes including three levels systematically resulted in higher importance values than attributes with only two. This handicaps the interpretation of importance values, given an unequal number of attribute-levels within the vignette design (Wittink, Krishnamurthi, \& Reibstein, 1990).

The data from Study 3 generally support the findings of Studies 1 and 2 . This is clearly the case with respect to PF and DF. It is also the case for 
$\mathrm{OV}_{\mathrm{GR}}$ negative/NPP negative which provides a negative part-worth utility whereas the part-worth utility of $\mathrm{OV}_{\mathrm{GR}}$ positive/NPP positive is positive. Furthermore, subjects' judgments of the vignettes from the perspective of fairness yield qualitatively very similar results to Study 2. The vignette considered fair and just scored higher than the vignette considered mid-fair and unjust (outcome valence kept stable). Moreover, fairness judgments fit well with the preference-ranking pattern of CA. Again here this links the relative rankings of CA with the scale-based overall satisfaction of a set of three selected vignettes.

\section{General Discussion}

We have gathered insights into people's fairness preferences with regard to a highly contested issue and the related decision processes. The data suggest that people's fairness judgments depend not only on the distributive and procedural justice but also on the specific context (outcome valence).

In radioactive waste management, fairness issues have been discussed for years and it has been widely acknowledged that fair processes are prerequisites for acceptance of a repository (e.g., Dietz \& Stern, 2008). Nevertheless, social scientific research in the past decades has strongly focused on people's perception and the management of risks, political trust and participation issues to explain opposition against nuclear waste disposal (NRC, 2001; Strandberg \& Andrén, 2009). What has hardly been empirically investigated, however, is people's concerns regarding justice in repository siting and their interplay with contextual factors such as the phasing out of nuclear or promoting of renewable energy. It was the aim of our study to shed light on this. The integrative total fairness model by Törnblom and Vermunt (1999) yielded a sound theoretical guidance, and CA was considered an appropriate technique to analyze main effects and to gain insights into the meaning of the three major factors: PF, DF, and the energy policy context $(\mathrm{OV})$.

The data of all the three studies indicate that situations with a fair process (i.e., clear rules, extended involvement of the public, and independent expertise) scored highest, whereas situations providing negative outcome valence (i.e., no geological repositories built, while at the same time replacement of nuclear facilities is considered) scored lowest. Although, CA data per se do not reflect people's total satisfaction with the vignettes on a given scale, the ranking data can still be clearly interpreted regarding the relative importance of the attributes in a given situation. Subjects' direct (scale based) ratings under the perspective of fairness of the three distinct vignettes confirm, however, what $\mathrm{CA}$ rankings and utility estimates indicate that: decision situations with fair procedures and just distributive principles score significantly higher than unfair ones; the process matters; people's fairness judgments are influenced by contextual factors as well. The latter suggests, in the issue at hand, that contextual factors such as energy policy do affect people's fairness judgments in addition to procedural and distributive justice. This is exactly what Törnblom and Vermunt (1999) postulated. Furthermore, vignette ratings indicate that people's fairness expectations are best satisfied in a situation where a 
fair process is in line with a just distribution rule and a positive or mid-positive outcome valence.

The similarities between the results of Studies 1 and 2, and under consideration of the adaptations in the design (i.e., in attribute OV) of Study 3 as well, are striking. This was not to be expected, as the subjects in the three studies differ markedly with respect to age, occupational status, education, and presumably political position (and study groups were recruited from different areas in the German-speaking part of Switzerland). This suggests, on one hand, that the methodological approach is robust with regard to individual and social context. We, furthermore, are convinced that we designed a sound vignette construct, as it is based on a theoretical model (Törnblom \& Vermunt, 1999), the concept of the recently launched site selection process in Switzerland (BFE, 2008b), and further case specific insights on the issue of radioactive waste disposal (NRC, 2001). This might allow for generalizing with regard to the issue at hand, as one would expect similar results in a randomized Swiss population sample. The data, furthermore, suggest that a fair procedure is a major requirement to potentially reach high preference of vignettes. In other words (a fair) procedure matters in repository siting.

The process might compete with situational conditions as the high importance of the attribute OV suggests. Still, we argue that in siting nuclear waste, a fair procedure is a prerequisite for the acceptance of the outcome, or, vice versa, a perceived unfair process would most likely result in non-acceptance of a repository. It has not, however, been investigated whether the model yields similar results among affected people (i.e., people living in an area under consideration for hosting a repository) as it is argued that the disposal of radioactive waste is a Not In My BackYard (NIMBY) phenomenon (e.g., Luloff, Albrecht, \& Bourke, 1998; Portney, 1991), i.e., people want to have the waste problem solved in general but not in their own residential area. We assume that this would result in a higher importance of the outcome valence vis-à-vis fairness aspects (Bauman \& Skitka, 2009).

There is empirical evidence (e.g., Dehghani et al., 2009; Skitka \& Mullen, 2002) that people who have "protected values," e.g., vis-à-vis the death penalty, would not sacrifice them even if this would result in negative consequences. It is questionable whether (all) the subjects in our studies harbor such protected values with respect to their position against nuclear energy (i.e., they would make no tradeoff with the fair process when the outcome contradicts their political and value based position). However, the higher dominance of this attribute is compensated by distributive (lower part-worth utilities) rather than by PF. This suggests that potential "sacred values" vis-à-vis nuclear energy and PF are both strongly anchored in these individuals and potentially conflict with each other. This corresponds to "tragic trade-offs [...] which pit sacred values against each other" (Tetlock, 2003, p. 322), and where "the decision task [is] emotionally stressful and difficult" (Hanselmann \& Tanner, 2008, p. 51), i.e., such a situation is much more difficult than when only one such "protected value" is given. We argue that people try to avoid such a situation and compensate instead with other factors such as distributive issues. In fact, our design brought subjects into delicate trade-off 
situations, where presumably their ideal decision situation was not among the vignettes given, and in which conflicting value-laden issues had to be coped with.

In reality, only a minority would probably consider all these issues to carefully ponder the pros and cons of the alternatives. It is more likely that a majority would follow simple heuristics like "fast and frugal" or others (e.g., Gigerenzer, 2008; Goldstein \& Gigerenzer, 2009; Hutchinson \& Gigerenzer, 2005). The subjects in our study were able to follow such heuristics but through the very procedure (reading carefully, detailed note taking, etc.) were influenced to reflect much more thoroughly than in real-life. On the other hand, a real situation is certainly much more complex and the corresponding attributes and attribute-levels can hardly be found in pure form as described in the vignettes. We asked people to rank a number of potential situations according to their preferences. However, there is no ranking in real-life, but usually just a yes or no required with respect to one concrete situation.

In our view, CA has the potential to be applied in justice research. It is claimed that CA is appropriate in handling complex, multi-factorial decision situations, and allowing for decomposing global preference judgments (Klein, 2002). CA has not been introduced in justice research even though trade-offs between PF and DF (and $\mathrm{OV}$, as we have shown) are evident and classical questionnaire approaches fail to account for this. A very similar methodological approach, factorial survey, is, however, well known in justice research allowing consideration of a number of individual and contextual factors (Jasso, 2006; Rossi, 1979). In contrast to CA, factorial survey uses rating instead of ranking. Either approach provides insights into the meaning of individual attributes - in any case relatively to the other attributes included in the design. However, we assumed that some attributes would strongly compete with each other (e.g., PF vs. OV, which we were interested in), and this is why we selected a "forced choice" approach (ranking). A factorial survey approach would probably not have met our needs here. However, as the cognitive effort demanded by CA is greater, factorial survey might be better suited to investigate further procedural sub-attributes such as respect, authenticity of experts, etc., referred to as interactional fairness (Bies \& Moag, 1986), and additional contextual factors.

\section{Conclusions}

Our results suggest that decision-processes should be given more attention by the political bodies. This holds especially in cases where a burden rather than a benefit has to be distributed, and where potential solutions are impacted by technical constraints. Such socio-technical interplays and the corresponding fairness issues have been almost always neglected in infrastructure siting. However, further and more in-depth studies are certainly necessary, as we were not able to cover all facets of justice. In addition, more context-related justice research is needed; we think this would meet regulators' and decision makers' needs, and in addition justice research would benefit from novel research questions. 
Acknowledgments We thank Heinz Gutscher for his valuable review of an early draft version and four anonymous reviewers for their critical reading and fruitful comments. Special thanks goes to the 192 participants who were willing to invest up to 2 hours to complete the survey, to our colleagues from the umbrella project for numerous discussions, to Sandro Bösch for his creativity and patience in optimizing the figures and tables, and to Heather Murray for her careful English check. This manuscript is part of a $\mathrm{PhD}$ thesis of the first author, which was sponsored by Swissnuclear.

\section{References}

Alexander, C. A., \& Becker, H. J. (1978). The use of vignettes in survey research. Public Opinion Quarterly, 42(1), 93-104.

Alriksson, S., \& Öberg, T. (2008). Conjoint analysis for environmental evaluation. A review of methods and applications. Environmental Science and Pollution Research, 15(3), 244-257.

Backhaus, K., Erichson, B., Plinke, W., \& Weiber, R. (2006). Multivariate Analysemethoden. Eine anwendungsorientierte Einführung [Multivariate methods. An application-oriented introduction] (11 überarb. ed.). Berlin: Springer. (in German).

Baron, J., \& Spranca, M. (1997). Protected values. Organizational Behavior and Human Decision Processes, 70(1), 1-16.

Bauman, C. W., \& Skitka, L. J. (2009). Moral disagreement and procedural justice: Moral mandates as constraints to voice effects. Australian Journal of Psychology, 61(1), 40-49.

Beck, M., \& Opp, K. D. (2001). Der faktorielle Survey und die Messung von Normen [Factorial survey and measurement of norms]. Kölner Zeitschrfit für Soziologie und Sozialpsychologie, 53(3), 283-306.

BFE. (2008a). Attitudes towards radioactive waste in Switzerland. Report. Bern: Swiss Federal Office of Energy.

BFE. (2008b). Sectoral plan deep geological repositories. Conceptual part. Retrieved from http://www.bfe.admin.ch/radioaktiveabfaelle/01277/index.html?lang=de\&dossier_id=05195.

Bies, R. J., \& Moag, J. S. (1986). Interactional justice: Communication criteria of fairness. In R. J. Lewicki, B. H. Sheppard, \& M. H. Bazerman (Eds.), Research on negotiation in organizations (pp. 43-55). Greenwich, CT: JAI Press.

Blader, S. L., \& Tyler, T. R. (2003). A four-component model of procedural justice: Defining the meaning of a "fair" process. Personality and Social Psychology Bulletin, 29(6), 747-758.

Colquitt, J. A., Conlon, D. E., Wesson, M. J., Porter, C. O., \& Ng, K. Y. (2001). Justice at the Millennium: A meta-analytic review of 25 years of organizational justice research. Journal of Applied Psychology, 86(3), 425-445.

COWAM 2. (2007). Quality of decision-making processes. Decision-making processes in radioactive waste governance - insights and recommendations. WP 3 (pdf). Paris.

Currim, I. S., Weiberg, C. B., \& Wittink, D. R. (1981). Design of subscriptions programs for a performing arts series. Journal of Consumer Research, 8(June), 67-75.

Dehghani, M., Iliev, R., Sachdeva, S., Atran, S., Ginges, J., \& Medin, D. (2009). Emerging sacred values: Iran's nuclear program. Judgment and Decision Making, 4(7), 930-933.

Deutsch, M. (1975). Equity, equality, and need: What determines which value will be used as the basis of distributive justice? Journal of Social Issues, 31(3), 137-149.

Dietz, T., \& Stern, P. C. (Eds.). (2008). Public participation in environmental assessment and decision making. Washington, DC: The National Academies Press.

Earle, T. C., \& Siegrist, M. (2008). On the relation between trust and fairness in environmental risk management. Risk Analysis, 28(5), 1395-1413.

Flüeler, T. (2006). Decision making for complex socio-technical systems. Robustness from lessons learned in long-term radioactive waste governance (Vol. 42). Dordrecht: Springer.

Folger, R., \& Cropanzano, R. (1998). Organizational justice and human resource management. Thousand Oaks, CA: SAGE.

Folger, R., Rosenfield, D., Grove, J., \& Corkran, L. (1979). Effects of "voice" and peer opinions on responses to inequity. Journal of Personality and Social Psychology, 37(12), 2253-2261.

Gibson, J. L. (1989). Understandings of justice: Institutional legitimacy, procedural justice, and political tolerance. Law \& Society Review, 23(3), 469-496.

Gigerenzer, G. (2008). Why heuristics work. Perspectives on Psychological Science, 3(1), 20-29. 
Goldstein, D. G., \& Gigerenzer, G. (2009). Fast and frugal forecasting. International Journal of Forecasting, 25(4), 760-772.

Green, P. E., Krieger, A. M., \& Wind, Y. (2001). Thirty years of conjoint analysis: Reflections and prospects. Interfaces, 31(3), S56-S73.

Green, P. E., \& Srinivasan, V. (1978). Conjoint analysis in consumer research-issues and outlook. Journal of Consumer Research, 5(2), 103-123.

Green, P. E., \& Srinivasan, V. (1990). Conjoint-analysis in marketing-new developments with implications for research and practice. Journal of Marketing, 54(4), 3-19.

Gunderson, W. C., \& Rabe, B. G. (1999). Voluntarism and its limits: Canada's search for radioactive waste-siting candidates. Canadian Public Administration, 42, 193-214.

Gustafsson, A., Hermann, A., \& Huber, F. (Eds.). (2007). Conjoint measurement. Methods and applications (4th ed.). Berlin: Springer.

Hanselmann, M., \& Tanner, C. (2008). Taboos and conflicts in decision making: Sacred values, decision difficulty, and emotions. Judgment and Decision Making Journal, 3(1), 51-63.

Hutchinson, J. M. C., \& Gigerenzer, G. (2005). Simple heuristics and rules of thumb: Where psychologists and behavioural biologists might meet. Behavioural Processes, 69(2), 97-124.

IAEA. (1994). Classification of radioactive waste. A safety guide. Vienna: International Atomic Energy Agency.

Jasso, G. (2006). Factorial survey methods for studying beliefs and judgments. Sociological Methods \& Research, 34(3), 334-423.

KASAM. (1988). Ethical aspects on nuclear waste (No. SKN 29). Stockholm: KASAM (Consultative Committee for Nuclear Waste Management).

Kasperson, R. E. (Ed.). (1983). Equity issues in radioactive waste management. Cambridge, MA: Oelgeschlager, Gunn \& Hain.

Kazemi, A., \& Törnblom, K. (2008). Social psychology of justice: Origins, central issues, recent developments, and future directions. Nordic Psychology, 60(3), 209-234.

Klein, M. (2002). Die Conjoint-Analyse: Eine Einführung in das Verfahren mit einem Ausblick auf mögliche sozialwissenschaftliche Anwendungen [Conjoint analysis: Introduction into the method and outlook into potential social scientific applications]. Köln: Zentralarchiv für Empirische Sozialforschung Universität zu Köln.

Krütli, P., Flüeler, T., Stauffacher, M., Wiek, A., \& Scholz, R. W. (2010a). Technical safety vs. public involvement? A case study on the unrealized project for the disposal of nuclear waste at Wellenberg (Switzerland). Journal of Integrative Environmental Sciences, 7(3), 229-244.

Krütli, P., Stauffacher, M., Flüeler, T., \& Scholz, R. W. (2010b). Functional-dynamic public participation in technological decision making: Site selection processes of nuclear waste repositories. Journal of Risk Research, 13(7), 861-875.

Leventhal, G. S. (1980). What should be done with equity theory? New approaches in the study of fairness in social relationships. In K. J. Gergen, M. S. Greenberg, \& R. S. Willis (Eds.), Social exchange. Advances in research and theory (pp. 27-55). New York: Plenum Press.

Leventhal, G. S., Karuza, J., Jr, \& Rick Fry, W. (1980). Es geht nicht nur um Fairness: Eine Theorie der Verteilungspräferenzen [It is not only fairness: A theory on distributive preferences]. In G. Mikula (Ed.), Gerechtigkeit und soziale Interaktion. Experimentelle und theoretische Beiträge aus der psychologischen Forschung [Justice and social interaction. Experimental and theoretical contributions from psychological research] (pp. 185-250). Bern: Verlag Hans Huber.

Liebig, S. (2001). Lessons from philosophy? Interdisciplinary justice research and two classes of justice judgments. Social Justice Research, 14(3), 265-287.

Lind, E. A., \& Tyler, T. R. (1988). The social psychology of procedural justice. New York: Plenum Press.

Luce, R. D., \& Tukey, J. W. (1964). Simultaneous conjoint-measurement-a new type of fundamental measurement. Journal of Mathematical Psychology, 1(1), 1-27.

Luloff, A. E., Albrecht, S. L., \& Bourke, L. (1998). NIMBY and the hazardous and toxic waste siting dilemma: The need for concept clarification. Society \& Natural Resources, 11, 81-89.

Nagra. (2002). Project opalinus-safety report: Demonstration of disposal feasibility for spent fuel, vitrified high-level waste and long-lived intermediate level waste (Entsorgungsnachweis) (No. NTB 02-05). Wettingen: Nagra.

NEA. (1999). Strategic areas in radioactive waste management. The viewpoint and work orientations of NEA Radioactive Waste Management Committee. Paris: OECD/NEA.

NEA. (2008). Moving forward with geological disposal of radioactive waste (pdf No. 6433). Paris: OECD/NEA. 
NRC. (2001). Disposition of high-level waste and spent nuclear fuel: The continuing societal and technical challenges. Washington, DC: National Academies Press.

Pescatore, C., \& Vari, A. (2006). Stepwise approach to the long-term management of radioactive waste. Journal of Risk Research, 9(1), 13-40.

Portney, K. E. (1991). The NIMBY syndrome. New York: Auburn House.

Ratcliffe, J. (2000). Public preferences for the allocation of donor liver grafts for transplantation. Health Economics, 9(2), 137-148.

Rawles, K. (2002). Compensation in radioactive waste management: Ethical issues in the treatment of host communities ( $p d f)$. Oxfordshire: Nirex.

Renn, O., Webler, T., \& Wiedemann, P. (Eds.). (1995). Fairness and competence in citizen participation: Evaluating models for environmental discourse. Dordrecht: Kluwer.

Rosa, E. A., \& Freudenberg, W. R. (1993). The historical development of public reactions to nuclear power: Implications for nuclear waste policy. In R. E. Dunlap, M. E. Kraft, \& E. A. Rosa (Eds.), Public reactions to nuclear waste: Citizens' views of repository siting (pp. 32-63). Durham, NC: Duke University Press.

Rossi, P. H. (1979). Vignette analysis: Uncovering the normative structure of complex judgments. In R. K. Merton, J. S. Coleman, \& P. H. Rossi (Eds.), Qualitative and quantitative social research. Papers in honor of Paul F. Lazarsfeld (pp. 176-186). New York: The Free Press.

Rossi, P. H., \& Nock, S. L. (Eds.). (1982). Measuring social judgments. Beverly Hills: SAGE.

Sattler, H., \& Hensel-Börner, S. (2007). A comparison of conjoint measurement with self-explicated approaches. In A. Gustafsson, A. Hermann, \& F. Huber (Eds.), Conjoint measurement. Methods and applications. Berlin: Springer.

Sjöberg, L., \& Drottz-Sjöberg, B.-M. (2001). Fairness, risk and risk tolerance in the siting of a nuclear waste repository. Journal of Risk Research, 4(1), 75-101.

Skitka, L. J. (2002). Do the means always justify the ends, or do the ends sometimes justify the means? A value protection model of justice reasoning. Personality and Social Psychology Bulletin, 28(5), $588-597$.

Skitka, L. J. (2003). Are outcome fairness and outcome favorability distinguishable psychological constructs? A meta-analytic review. Social Justice Research, 16(4), 309-341.

Skitka, L. J., \& Mullen, E. (2002). Understanding judgments of fairness in a real-world political context: A test of the value protection model of justice reasoning. Personality and Social Psychology Bulletin, 28(10), 1419-1429.

Stauffacher, M., Krütli, P., \& Scholz, R. W. (Eds.). (2008). Gesellschaft und radioaktive Abfälle: Ergebnisse einer schweizweiten Befragung [Society and radioactive waste: Results of a survey in Switzerland]. Zürich, Chur: Rüegger.

Stern, P. C., \& Fineberg, V. (Eds.). (1996). Understanding risk: Informing decisions in a democratic society. Washington, DC: National Academies Press.

Strandberg, U., \& Andrén, M. (2009). Editorial: Nuclear waste management in a globalised world. Journal of Risk Research, 12(7-8), 879-895.

Surrey, J., \& Huggett, C. (1976). Opposition to nuclear power. A review of international experience. Energy Policy, 4(4), 286-307.

Tanner, C., Ryf, B., \& Hanselmann, M. (2009). Geschützte Werte (GWS): Konstruktion und Validierung eines Messinstrumentes [Sacred values: Construction and validation of a measurement instrument]. Diagnostica, 55(3), 174-183.

Tetlock, P. E. (2003). Thinking the unthinkable: sacred values and taboo cognitions. Trends in Cognitive Sciences, 7(7), 320-324.

Thibaut, J., \& Walker, L. (1975). Procedural justice: A psychological analysis. Hillsdale, NJ: Erlbaum.

Thibaut, J., \& Walker, L. (1978). A theory of procedure. California Law Review, 66(3), 541-566.

Törnblom, K. Y. (1988). Positive and negative allocations: A typology and a model for conflicting justice principles. In E. Lawler \& B. Markovsky (Eds.), Advances in group processes (Vol. 5, pp. 141-168). Greenwich, CT: Jai Press.

Törnblom, K. Y., \& Kazemi, A. (2010). Justice judgments of physical abuse and theft: The importance of outcome and procedure. Social Justice Research, 23(4), 308-328.

Törnblom, K. Y., \& Vermunt, R. (1999). An integrative perspective on social justice: Distributive and procedural fairness evaluations of positive and negative outcome allocations. Social Justice Research, 12(1), 39-64.

Törnblom, K. Y., \& Vermunt, R. (2007a). Towards integrating distributive justice, procedural justice, and social resource theories. Social Justice Research, 20(3), 312-335. 
Törnblom, K. Y., \& Vermunt, R. (Eds.). (2007b). Distributive and procedural justice. Research and social applications. Hampshire: Ashgate.

Tyler, T. R. (1988). What is procedural justice-criteria used by citizens to assess the fairness of legal procedures. Law \& Society Review, 22(1), 103-135.

Tyler, T. R., Boeckmann, R. J., Smith, H. J., \& Huo, Y. J. (1997). Social justice in a diverse society. Boulder, CO: Westview Press.

van den Bos, K., Lind, E. A., \& Wilke, H. A. M. (2001). The psychology of procedural and distributive justice viewed from the perspective of fairness heuristic theory. Justice in the Workplace from Theory to Practice, 2(2), 49-66.

van den Bos, K., Wilke, H. A. M., Lind, E. A., \& Vermunt, R. (1998). Evaluating outcomes by means of the fair process effect: Evidence for different processes in fairness and satisfaction judgments. Journal of Personality and Social Psychology, 74(6), 1493-1503.

Wallander, L. (2009). 25 years of factorial survey in sociology: A review. Social Science Research, 38(3), 505-520.

Webler, T., \& Tuler, S. (2000). Fairness and competence in citizen participation-theoretical reflections from a case study. Administration \& Society, 32(5), 566-595.

Witherspoon, P. A., \& Bodvarsson, G. S. (Eds.). (2001). Geological challenges in radioactive waste isolation: Third worldwide review. Berkeley: Lawrence National Laboratory.

Wittink, D. R., Krishnamurthi, L., \& Nutter, J. B. (1982). Comparing derived importance weights across attributes. Journal of Consumer Research, 8(March), 471-474.

Wittink, D. R., Krishnamurthi, L., \& Reibstein, D. J. (1990). The effect of differences in the number of attribute levels on conjoint results. Marketing Letters, 1(2), 113-123. 